\title{
Mutagen Formation on Photolysis of Dehydroacetic Acid
}

\author{
Tsutomu YamaguchI \\ Department of Living and Health, Joetsu University of Education, \\ Joetsu, Niigata 943, Japan
}

Received July 14, 1986

\begin{abstract}
Dehydroacetic acid (DHA) gave rise to some mutagenic substances on irradiation with ultraviolet (UV) light. Mutagenicity was detected toward Salmonella typhimurium TA 100 without the S-9 mix. A decrease in the absorbance maximum at $307 \mathrm{~nm}$ of DHA was accompanied by a simultaneous increase in total carbonyls and a slight decrease in $\mathrm{pH}$. The mutagenicity of the substances derived from DHA was reduced by the addition of reducing agents, which suggested that the mutagenic substances might be carbonyl compounds. From the results of analysis of carbonyl compounds by GC-mass spectrometry and determination of their mutagenicities in the UV-irradiated DHA sample, it was confirmed that the mutagenicity of the sample was mainly due to 2-pentenal.
\end{abstract}

Sorbic acid and dehydroacetic acid (DHA) have relatively low toxicities themselves, and so are widely used as preservatives in juices, and bakery and daily products. In Japan, sorbic acid and DHA, as additives, are regulated to be used less than $0.2 \%$ for sorbic acid and $0.05 \%$ for DHA, respectively. ${ }^{1}$

Arya $^{2)}$ reported that sorbic acid in aqueous solution undergoes autoxidation, leading to the formation of malonaldehyde and other carbonyls. Harada et al. ${ }^{3)}$ reported that acetone and a polymer were produced on the reaction of sorbic acid with hydrogen peroxide. Namiki and $\mathrm{Kada}^{4)}$ reported the formation of ethyl nitrolic acid on the reaction of sorbic acid with sodium nitrite. Ishizeki et al. ${ }^{5 \text { ) }}$ reported that sorbic acid gave rise to an antibacterial substance on radiolysis of a solution of it.

DHA seems to show some similarities in structure with sorbic acid (trans,trans-2,4hexadienoic acid), because if the lactone ring of DHA is hydrolyzed, 2-acetyl-3-hydroxy2,4-hexadienoic acid or 2-acetyl-3-hydroxy-5oxo-2-hexanoic acid may be yielded. However, there have been few reports of its degradation.

We have described some mutagenic substances in foods. ${ }^{69)}$ In the course of those studies, we found that DHA, when degraded on irradiation with ultraviolet (UV) light, gave rise to some mutagenic substances for Salmonella. Sorbic acid also, when degraded by UV, yielded some mutagenic substances, but the amount was much smaller than in the case of DHA.

UV-irradiation has been used for the sterilization on microorganisms in many foods. We studied the mutagenic substances produced on UV-irradiation of DHA.

This report deals with the results.

\section{MATERIALS AND METHODS}

Mutagenicity assay. The mutagenicity assay was carried out according to Ames et al. with some modifications. ${ }^{10}$ The histidine-requiring strains of Salmonella typhimurium were supplied by Dr. B. N. Ames. A mixture of the test strain, the sample and a phosphate buffer or the S-9 mix was incubated at $37^{\circ} \mathrm{C}$ for $20 \mathrm{~min}$ and then poured on to an agar layer. After incubation at $37^{\circ} \mathrm{C}$ for $48 \mathrm{hr}$, His ${ }^{+}$ revertant colonies were counted. The mutagenicity test was performed at five concentration levels for each sample, and the highest potency obtained from the doseresponse curve is presented in this paper.

Photolysis of DHA and sorbic acid. Ten $\mathrm{ml}$ of $0.1 \%$ DHA (sodium salt) or sorbic acid (potassium salt) in distilled water was placed in a $9-\mathrm{cm}$ petri dish containing a 
magnetic stir bar. The dish was put into an irradiation box and then a UV light lamp (High intensity-UV lamp, type UVGL-58; UVP Inc., San Gabriel, CA 91778, USA) was used to irradiate the dish from a distance of $15 \mathrm{~cm}$. The intensities were: $300 \mu \mathrm{W} / \mathrm{cm}^{2} / \mathrm{sec}$ for the short wave lamp $(254 \mathrm{~nm})$ and $600 \mu \mathrm{W} / \mathrm{cm}^{2} / \mathrm{sec}$ for the long wave $(360 \mathrm{~nm})$ lamp, respectively.

A portion of a sample was withdrawn at various intervals during the irradiation period, which was then assayed for mutagenicity and reaction products.

Total carbonyls were measured according to Sanders and Schubert ${ }^{11)}$ using $0.1 \mathrm{~N} \mathrm{HCl}$ instead $0.01 \mathrm{~N} \mathrm{HCl}$.

Preparation of DNPH-derivatives of photolysis products. One $\mathrm{ml}$ of a UV-irradiated sample was put into a glassstoppered test tube of $5 \mathrm{ml}$ volume, and then $0.3 \mathrm{ml}$ of $1 \%$ dinitrophenylhydrazine (DNPH) in $3 \% \mathrm{HCl}$-methanol solution was added to and mixed with it. After the mixture had stood at room temperature for $2 \mathrm{hr}, 0.3 \mathrm{ml}$ of chloroform was added and the DNPH-derivatives formed were extracted with chloroform.

GC-mass spectrography. A Shimadzu GCMS-QP 1000 GC-mass spectrometer system was used. A standard glass column $(2 \mathrm{~m} \times 2.6 \mathrm{~mm}$ i.d. $)$ was packed with $5 \% \mathrm{SP}-2100$ Chromosorb-W (80 100 mesh). The flow rate of gas $(\mathrm{He})$ was $40 \mathrm{ml} / \mathrm{min}$ and the column temperature was programmed from $170^{\circ} \mathrm{C}$ to $280^{\circ} \mathrm{C}$ at $8^{\circ} \mathrm{C} / \mathrm{min}$. The injection and separator temperatures were $300^{\circ} \mathrm{C}$. Samples (DNPHderivatives in chloroform) were injected into the column, and the peak substances were analyzed with the mass spectrometer.

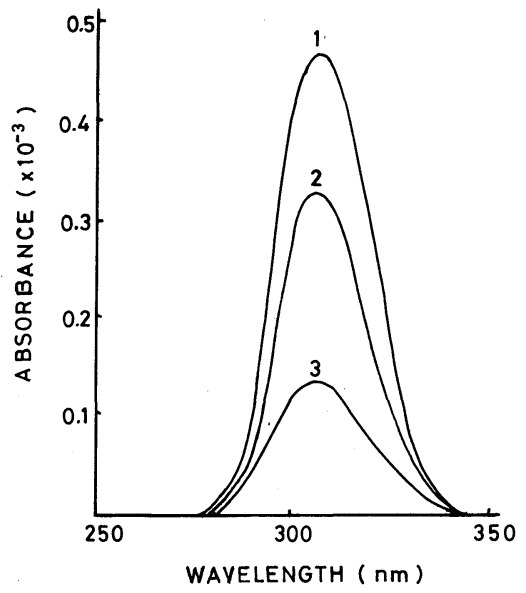

FIG. 1. Changes in the Absorption Spectrum of an Aqueous Solution of DHA $(0.1 \%$; pH 5.0) during Short Wave UV-irradiation.

(1) fresh; (2) and (3) after 1 and $3 \mathrm{hr}$ irradiation, respectively. Absorbance was measured after 100-times dilution.

\section{RESULTS AND DISCUSSION}

\section{Photolysis of DHA by UV-irradiation}

DHA in aqueous solution shows a strong absorption maximum at $307 \mathrm{~nm}\left(E_{1 \%}^{307} 473\right)$ due to the conjugated double bond in its molecule. During UV-irradiation, however, the intensity decreased considerably (Fig. 1).

The degradation showed a linear relationship with irradiation time. After $3 \mathrm{hr}$ UVirradiation, $E_{1 \%}^{307}$ had decreased from 473 to 140. The degradation occurred with UV-light of both short $(254 \mathrm{~nm})$ and long $(360 \mathrm{~nm})$ wave length, and a little degradation was observed on exposure to luminescence. The decrease in absorbance at $307 \mathrm{~nm}$ was accompanied by a simultaneous increase in total carbonyls and a slight decrease in $\mathrm{pH}$ (Fig. 2).

\section{Formation of mutagenic substances from $\mathrm{DHA}$ on $U V$-irradiation}

Figure 3 shows the time-course of the formation of mutagenic substances from DHA on UV- or luminescence-irradiation.

When an aqueous solution of DHA was

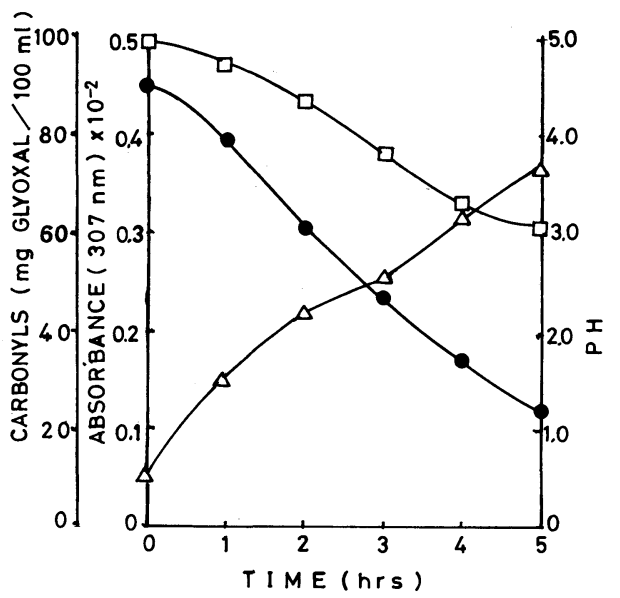

FIG. 2. Changes in pH, Total Carbonyls and Absorbance of Aqueous Solution of DHA.

DHA $(0.1 \%$ in distilled water) was irradiated with short wave UV-light as described in the text. Portions of the irradiated samples were withdrawn at regular intervals as indicated, and then the carbonyls, absorbance and $\mathrm{pH}$ were determined as described in the text. $\square-\square, \mathrm{pH}$; - - absorbance; $\triangle-\triangle$, carbonyls. 


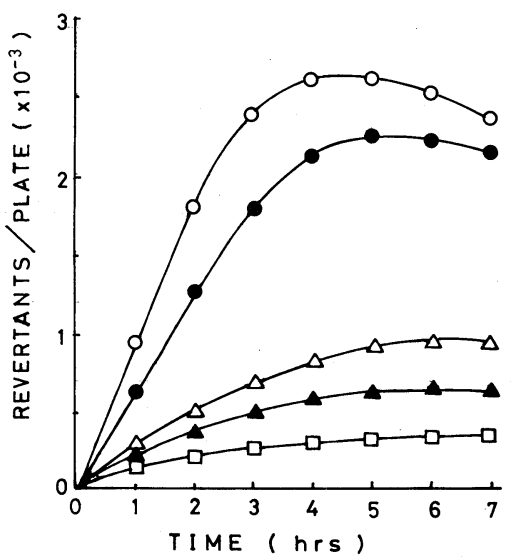

FIG. 3. Time-course of the Formation of Mutagenic Substances from DHA and Sorbic Acid on UVirradiation.

DHA or sorbic acid solutions $(0.1 \%$;H 5.0$)$ were irradiated with short or long wave UV- or luminescent-light. Portions of the irradiated samples $(1.0 \mathrm{ml})$ were withdrawn at regular intervals as indicated, and then the mutagenicity was assayed by the standard method. $\bigcirc-\bigcirc$, DHA-short wave UV; - DHA-long wave UV; $\triangle-\triangle$, sorbic acid-short wave $U V ; \boldsymbol{\Lambda}-\boldsymbol{\Delta}$, sorbic acid-long wave $U V$; $\square-\square$, DHA-luminescent-light.

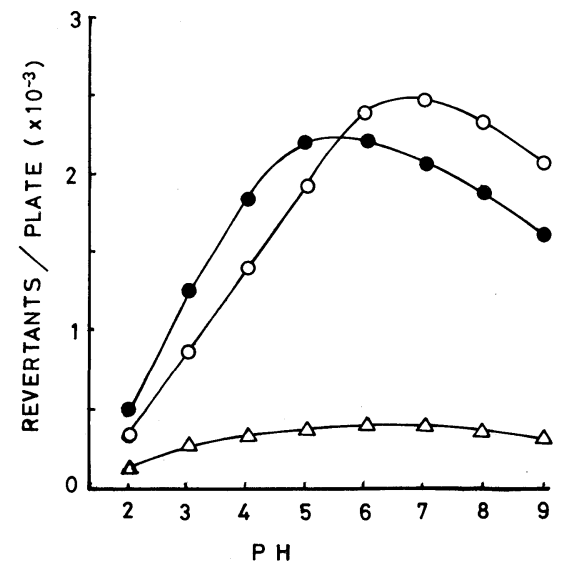

FIG. 4. The Effect of $\mathrm{pH}$ on the Formation of Mutagenic Substances from DHA on UV-irradiation.

DHA was dissolved in various buffers at the concentration of $0.1 \%$. Each solution was irradiated with short or long wave UV- or luminescent-light for $5 \mathrm{hr}$. Portions of the irradiated samples $(0.1 \mathrm{ml})$ were withdrawn, and then the mutagenicity was assayed by the standard method. The buffer solutions used were: $0.2 \mathrm{M}$ acetate buffer, $\mathrm{pH} 2 \sim 4$; $0.1 \mathrm{M}$ phosphate buffer, $\mathrm{pH} 5.0 \sim 7.0 ; 0.1 \mathrm{M}$ phosphatesodium hydroxide buffer, $\mathrm{pH} 8.0 \sim 9.0$. $\bigcirc-\bigcirc$, long wave $\mathrm{UV}$; - - , short wave UV; $\triangle-\triangle$, luminescent-light. exposed to short or long wave UV-light, mutagenicity markedly appeared in proportion to the irradiation time, and became maximum after $5 \mathrm{hr}$, but further irradiation reduced the mutagenicity. Under luminescent-light, a little mutagenicity was seen after irradiation for a long time.

Exposure of sorbic acid to UV-light of both wavelengths also formed mutagenic substances but the amount formed was less than that in the case of DHA. But on exposure of sorbic acid to luminescent-light, no mutagenicity was observed during $24 \mathrm{hr}$-irradiation.

Figure 4 shows the effect of $\mathrm{pH}$ on the formation of mutagenic substances from a DHA solution on UV-irradiation.

The maximum formation of the mutagenic substances occurred at $\mathrm{pH} 5.5$ on short wave and 6.5 on long wave UV-irradiation. The formation of mutagenic substances rather decrease in acidic or alkaline conditions.

\section{Effects of reducing agents on the mutagenicity}

It is probable from Fig. 2 that the mutagenic substances formed from DHA on UV-

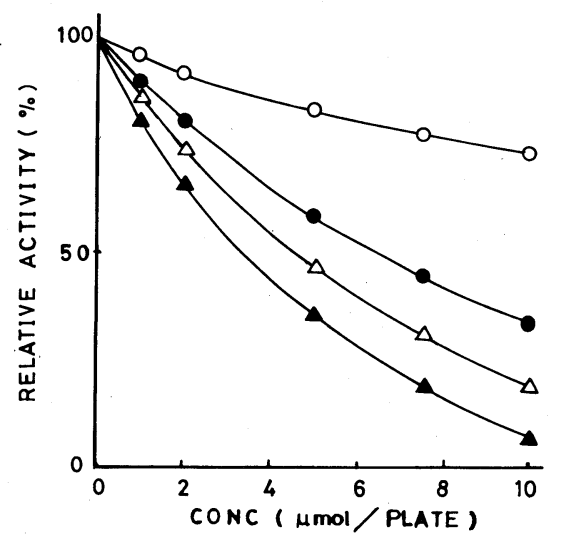

FIG. 5. Effect of Reducing Agents on the Mutagenic Substance from DHA on UV-irradiation.

A reaction mixture containing $0.1 \mathrm{ml}$ of Salmonella TA 100 cells, $0.1 \mathrm{ml}$ of a UV-irradiated DHA solution, $0.1 \mathrm{ml}$ of a reducing agent solution and $0.25 \mathrm{ml}$ of phosphate buffer was preincubated at $37^{\circ} \mathrm{C}$ for $20 \mathrm{~min}$. After this treatment, the mutagenicity was assayed by the standard method. The number of revertants without a reducing agent was 2,455. $\bigcirc-\mathrm{O}, \mathrm{NaHSO}_{3} ; \mathrm{O}-\mathrm{GSH} ; \triangle-\triangle$, cysteine; $\boldsymbol{\Delta}-\boldsymbol{\Delta}, \mathrm{Na}_{2} \mathrm{~S}_{2} \mathrm{O}_{3}$. 
irradiation are some carbonyl compounds. If the mutagenic substances are carbonyl compounds, their mutagenicities will be abolished on chemical reduction with some reducing agents. To confirm this, the effects of some reducing agents were determined on the mutagenicity detected on UV-irradiation of DHA (Fig. 5).

The mutagenicity was markedly reduced by the addition of all the reducing agents tested. In particular, sodium thiosulfate abolished the mutagenicity completely at the concentration of $10 \mu \mathrm{mol} / \mathrm{plate}$. These results suggest that the mutagenic substances may be carbonyl compounds.
Analysis of carbonyl compounds produced from DHA on $U V$-irradiation

Figure 6 shows the gas chromatograms of DNPH-derivatives of carbonyl compounds produced from DHA on UV-irradiation.

In this figure, about eight new peaks can be observed for the 5-hr-irradiated sample of DHA. Peak no. 5 was the greatest in quantity of these peaks. Each peak was identified with a mass spectrometer.

Table I shows the confirmed formula for each peak.

With the exceptions of peak nos. 7 and 8, all the peaks were identified in the form of DNPH-derivatives. The greatest peak in Fig.

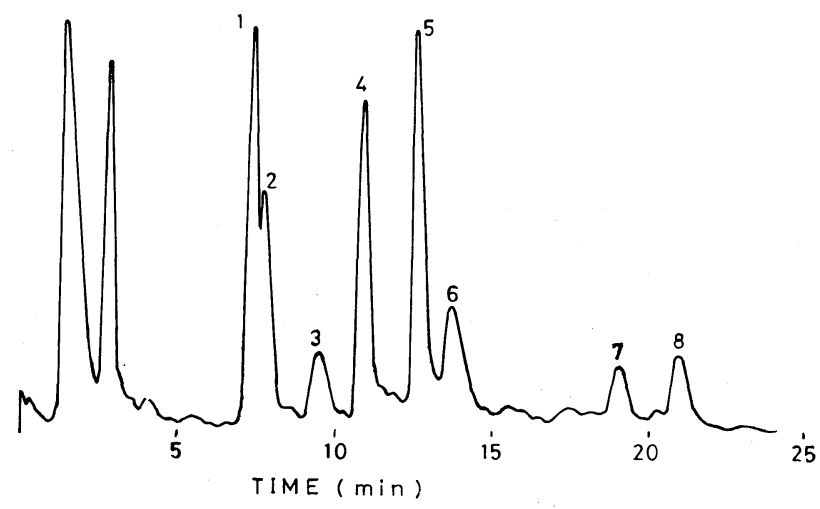

Fig. 6. Gas Chromatograms of DNPH-derivatives of Substances Produced from DHA on UV-irradiation. Column, glass $(2 \mathrm{~m} \times 2.6 \mathrm{~mm}$ i.d. $)$ packed with $5 \%$ SP-2100 Chromosorb-W; carrier gas, He, $40 \mathrm{ml} / \mathrm{min}$; column temperature, programmed from 170 to $280^{\circ} \mathrm{C}$ at $8{ }^{\circ} \mathrm{C} / \mathrm{min}$; injection temperature, $300^{\circ} \mathrm{C}$.

Table I. Substances Identified in the Peaks of the Gas Chromatograms with A MASS Spectrometer

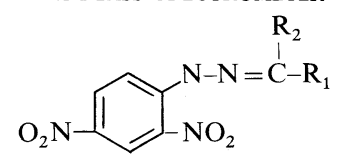

\begin{tabular}{ccll}
\hline Peak No. & MW & \multicolumn{1}{c}{$\begin{array}{c}\text { Molecular } \\
\text { Formula }\end{array}$} & \multicolumn{1}{c}{$\begin{array}{c}\text { Identified } \\
\text { substance }\end{array}$} \\
\hline 1 & 180 & - & 2,4-Dinitroaniline \\
2 & 210 & $\mathrm{R}_{1}: \mathrm{H}, \mathrm{R}_{2}: \mathrm{H}$ & Formaldehyde \\
3 & 224 & $\mathrm{R}_{1}: \mathrm{H}_{2}, \mathrm{R}_{2}: \mathrm{CH}_{3}$ & Acetaldehyde \\
4 & 238 & $\mathrm{R}_{1}: \mathrm{CH}_{3}, \mathrm{R}_{2}: \mathrm{CH}_{3}$ & Acetone \\
5 & 264 & $\mathrm{R}_{1}: \mathrm{H}_{2}, \mathrm{R}_{2}: \mathrm{C}_{4} \mathrm{H}_{7}$ & 2-Pentenal \\
6 & 282 & $\mathrm{R}_{1}: \mathrm{CH}_{3}, \mathrm{R}_{2}: \mathrm{C}_{2} \mathrm{H}_{3} \mathrm{O}_{2}$ & Acetoacetic acid \\
7 & 330 & Unknown & - \\
8 & 330 & Unknown & - \\
\hline
\end{tabular}


Table II. Mutagenicities of the Carbonyl COMPOUNDS PRODUCED FROM DHA ON UV-IRRADIATION

Each compound $(0.1 \mathrm{ml})$ was preincubated with $0.1 \mathrm{ml}$ of Salmonella TA 100 cells and $0.25 \mathrm{ml}$ of phosphate buffer at $37^{\circ} \mathrm{C}$ for $20 \mathrm{~min}$. After this treatment, the mutagenicities were assayed by the standard method.

\begin{tabular}{lcc}
\hline $\begin{array}{c}\text { Carbonyl } \\
\text { compound }\end{array}$ & $\begin{array}{c}\text { Dose } \\
(\mu \mathrm{g} / \text { plate })\end{array}$ & $\begin{array}{c}\text { Mutagenicity } \\
(\text { Revertants/plate })\end{array}$ \\
\hline Formaldehyde & 50 & 187 \\
Acetaldehyde & 100 & 72 \\
Acetone & 100 & 50 \\
2-Pentenal & 50 & 2,253 \\
Acetoacetic acid & 50 & 126 \\
\hline
\end{tabular}

6 (peak no. 5) was confirmed to be 2-pentenal.

\section{Mutagenicities of the identified carbonyl com- pounds}

The mutagenicities of pure sample of the identified carbonyl compounds derived from DHA on UV-irradiation were determined using Salmonella strains.

As shown in Table II, 2-pentenal showed high mutagenicity toward Salmonella typhimurium TA 100 without the S-9 mix. Formaldehyde also showed moderate mutagenicity but the other carbonyl compounds showed no mutagenicity toward this strain.

From the results of quantitative analysis and the mutagenicity of 2-pentenal in the UVirradiated DHA sample indicated that about $70 \%$ of the mutagenicity of the sample might be due to 2-pentenal itself, and it was also estimated that about $10 \%$ of the mutagenicity of the sample might be due to formaldehyde.

In the previous paper, ${ }^{12)}$ we reported the mutagenicities of various aldehydes toward Salmonella. It was found that $\alpha, \beta$-unsaturated aldehydes showed high mutagenicities, whereas saturated alkyl aldehydes did not. The same tendency can also be observed in Table II.

Although the mechanism of the formation of 2-pentenal has not been clarified so far, it can be assumed that the formation involves the condensation of two moles of acetaldehyde and one mole of formaldehyde, both of which are derived from DHA on UV-irradiation.

In foods, there are a lot of factors such as $\mathrm{pH}$, metal ions, amino acids, sugars, lipids and food additives. It is possible that these factors influence the stability of DHA in a negative or positive way. It is important to determine how DHA consists in various daily foods under UV-light. So further studies on the degradation of DHA will be performed under various conditions.

\section{REFERENCES}

1) I. Kawashiro, S. Fujii and H. Iwaida, "Shokuhin Tenkabutsu Handbook," Koseikan, Tokyo, Japan, 1983, p. 206.

2) S. S. Arya, J. Agric. Food Chem., 25, 1246 (1980).

3) K. Harada, R. Higuchi, M. Otani and I. Utsumi, Shokueishi, 10, 32 (1969).

4) M. Namiki and T. Kada, Agric. Biol. Chem., 39, 1335 (1975).

5) C. Ishizeki, Y. Kido, G. Urakubo and K. Satoh, J. Hygienic Chem., (Japan), 18, 337 (1972).

6) T. Yamaguchi and Y. Yamashita, Agric. Biol. Chem., 44, 1675 (1980).

7) T. Yamaguchi, Agric. Biol. Chem., 44, 3017 (1980).

8) T. Yamaguchi and K. Nakagawa, Agric. Biol. Chem., 47, 2461 (1983).

9) T. Yamaguchi, Agric. Biol. Chem., 49, 1979 (1975).

10) T. Yahagi, Tampakushitsu Kakusan Koso, 20, 1178 (1975).

11) E. B. Sanders and J. Schubert, Anal. Chem., 43, 59 (1971).

12) T. Yamaguchi, Bull. Joetsu University of Education, 5, 253 (1986). 